\title{
Exploring Teachers' Attitudes towards Teachers' Learning Community in Government Schools in Kuwait
}

\author{
Dr. Iqbal Al Shammari \\ Gulf University for Science \& Technology, Kuwait \\ Dr. Janet Testerman \\ Gulf University for Science E Technology, Kuwait \\ Dr. Florentina Halimi \\ Gulf University for Science \& Technology, Kuwait
}

Doi: 10.36941/jesr-2020-0o19

\begin{abstract}
Teachers' learning communities (TLC) provide life-long learning experience for teachers to acquire and improve their teaching. One case of TLC in a government school in Kuwait is described and analyzed. Results gained from this research study indicated positive attitudes towards TLCs. However, lack of teachers' willingness to apply what they learn, and the lack of the school leadership support, and teachers' autonomy were some of the challenges facing the successful creation of TLC. School leaders should foster the application of TLCs in schools by ensuring teachers' willingness to participate, encouraging teachers' interaction, providing effective leadership support, and motivating teachers to apply what they learn in their classrooms.
\end{abstract}

Keywords: TLC; leadership; willingness; collaboration; Kuwait

\section{Introduction}

A teacher's learning community TLC can be defined as a group of teachers who work collaboratively to reflect on their teaching practices, and relate their teaching practices to student's outcomes. (DuFour, 2004; Hord, 2008; McLaughlin \&Talbert, 2006; Stoll \& Louis, 2007). A TLC consists of teachers who meet regularly and work as a team to discuss shared topics, exchange practices and concerns, and brainstorm practical solutions for improving students' learning (Hord \& Sommers, 2008; Vescio, Ross \& Adams, 2008). Printy and Marks (2006) pointed out that creating TLC in schools can change the bureaucratic system of the schools to a more 'democratic' environment that consists of teachers' collective networking. Networking with other teachers and educators helps teachers reflect critically on their instruction and identify where their instructional practices in classrooms stand in terms of national and international practices.

Watkins (2005) described TLC as the 'key feature' of today's schools. Watkins also pointed out that creating TLC leads to higher students' achievement and engagement. Similarly, DuFour and Eaker (1998) found that TLC was associated with enhanced academic achievement, and overall 
students' motivation to learn. Moreover, Berlinger-Gustafson (2004) connected TLC to teachers' commitment to the school's goals, higher engagement in the overall students' learning inside the school and the greater likelihood to inspire students to learn.

DuFour and Eaker (1998) pointed out that TLC requires three factors: a) stronger teachers' relationships; b) shared ideas, and c) common culture, and considered these factors vital for any teachers' development reform.

Up to the present time, in Kuwait, teachers' professional development researches are paid more attention in training offered by the Ministry of Education MOE as in seminars, and workshops. Not many studies focus on teachers' PLC, nevertheless, not many research studies focus on teachers' views in regard to PLC application in government schools.

\section{Literature Review}

\subsection{Teachers' Willingness to Apply What They Learn}

Bernshtock and Cohen (2014) interpreted teachers' willingness as teachers' intention to implement and adopt a proposed change. Copriady (2014) considered teachers' motivation as the mediator of teachers' willingness to apply what they learn in teaching. Similarly, Sang, Valcke, Van Braak, Tondeur and Zhu (2011) considered teachers' willingness as one variable among the complex teacherrelated variables affecting the application of new instructional methods. Moreover, Sarason (1996) pointed out that teachers' lack of readiness to apply new instructional methods leads to an increased resistance to change.

According to Bernshtock and Cohen (2014), lack of teachers' willingness to participate in learning communities increased teachers' resistance to implement the proposed change. Abu Zeid, Assadi, and Murad (2017) stressed the need to 'nurture' teachers' motivation in order to ensure their willingness to apply the new instructional methods. On the other hand, teachers' anxiety and fear of change were found as reasons behind the lack of desire or weak willingness for implementation (Bernshtock \& Cohen, 2014).

In an attempt to apply new Web 2.0 technologies, Sakal, Matković and Tumbas (2012) investigated the points of views of three groups of stakeholders involved in the education process; students, parents and teachers. The results showed an increased awareness among the three stakeholders, but also an evident resistance and an increased amount of obligations. The researchers recommended giving all stakeholders involved in the education process more detailed information about the new idea and the benefits of implementation to ensure not only awareness but also willingness. Smolyaninova and Bezyzvestnykh (2019) carried out a research in a federal university aimed at improving the quality of teachers' training. Their research involved 63 teachers and 109 students. They claimed that teachers and students' realization of the benefits and their intensive engagement in and outside the classroom should be considered as important factors affecting teachers and students' willingness to apply what they learn.

Semenikhina and Drushlyak (2015) studied math teachers' willingness to use of Dynamic Mathematics Software DMS in the learning process and showed poor results not because of the limited number of computers in schools, but because of the lack of teachers' willingness of to apply such software. $68 \%$ of the teachers participated in the study did not deny the feasibility of the DMS applications, but noted their unwillingness to use them. Another research conducted by Savina (2015) studied the reasons behind secondary teachers' $(\mathrm{N}=562)$ lack of willingness to apply innovative methods during the professional development PD session in Russia and found seven reasons for lack of willingness as follow: 1) lack of time due to workload and lack of self-organization; 2) lack of information; 3) lack of advisory assistance; 4) insufficient financial incentives; 5) lack of confidence in abilities; 6) lack of the colleagues' support, and 7) irrelevance of the proposed PD ideas.

In their research on teachers' readiness, Kariyev et. al. (2018) showed a low level of readiness of teachers to apply the interactive teaching methods during their teachers' PD. $55 \%$ of the teachers 
were convinced of the importance of the new methods but also indicated their unwillingness to apply them.

\subsection{The School Leadership Support}

Rogers (2003) discussed several factors affecting teachers' decision to implement what teachers newly learn through the learning communities, such as teachers' personalities, technological factors and support of the school organizational leadership. School organizational leadership can be practiced by people occupying different tasks and roles such as the school principal, vice principal, subjects' supervisors and Head of Departments HODs. (Dutro et. al, 2002; Ford, 1992; Fullan, 2014; O’Day, 2002) suggested that teachers' implementation of what they learn as new teaching method derives from the leaders' support in their schools which functions as the ground to teachers' decisions regarding implementation and/or adoption of newly learned teaching techniques or methods. Therefore, the school' leadership can ensure the success or failure of learning communities. Studies indicate that teachers tend to implement new teaching methods, strategies, or techniques if they happen to be under the support and supervision of their leaders (Bryk, 2010).

The school leaders' support of learning communities is a complex topic that includes a system of approval of implementation, allowing time for teachers' collaboration, providing resources for implementation, participating in their PD meetings, providing reflective feedback and showing other teachers care and appreciation. Therefore, leaders' support in the TLCs especially implementation of what they learn in their classes should be considered and be forced by the school as a requirement to participate in any future PD. However, Bredeson and Johansson (200o) argued that school leaders should "encourage, nurture and support teacher learning, not to be the gatekeepers or governors of teacher professional development” (p. 390).

In large-sample research studies, positive results showed a high correlation between the success of TLC and the school's leadership support (Day, Harris, Hadfield, Tolley \& Beresford , 2002; Elmore, 2008; Heck, 1992; Robinson, 2007; Stoll \& Louis, 2007). For example, leaders (such as the school principals, HODs, and the subject supervisors) provide teachers with instrumental and emotional support (Beam, Chuansheng \& Greenberger, 2002; Leithwood, 1992) needed to form and develop successful TLCs.

\subsection{Teachers' Autonomy}

Current concepts and measures of TLC assume that once teachers' autonomy exists, existence and effectiveness of TLC can be guaranteed (Ramos, 2006). The case study conducted by Day, Harris, Hadfield, Tolley and Beresford (2000) on 12 English schools identified seven tensions face school principals. Among these tensions existed teachers' autonomy. Researchers such as Benson (2001) and Boote (2006) defined teachers' autonomy as teachers' freedom to choose what to teach and how to teach and to create their own 'initiatives' then 'apply them'. Littlewood (1997) viewed teachers' autonomy as "an independent capacity to make and carry out choices" depending on two main components: teachers' ability and teachers' willingness (p. 428). Similarly, Huang (2005) defined teachers' autonomy as "teachers' willingness, capacity and freedom to take control of their own teaching and learning” (p. 4). Another definition of teachers' autonomy was suggested by Pearson and Moomaw (2005) which connected teachers' autonomy to teachers' commitment. Finally, Schibeci and Hickey (2003) and Peters (2004) viewed teachers' autonomy as the motive to engage in instructional activities related to their diverse roles including their role in creating a learning community.

In his paper on teachers' autonomy and training, Lazăr (2013) pointed that in Romania teachers' training fails due to lack of teachers' autonomy causing teachers a problem diagnosing their own training or learning needs, which will then create another problem implementing these initiatives with their own students. Thus, Lazăr recommended that teachers' autonomy "should be the aim of 
any teacher in training for the future" (p. 464).

Ingersoll (2003) reported low teachers' autonomy because of external regulations and pressures from the school leaders. Whereas, Peters (2004) pointed out that teachers' lack of autonomy, work load, and lack of time were reasons why professional development efforts fail, and suggested that professional development plans should be created as action research to enable better investigation of the effects of teachers' autonomy on teachers' professional development.

This paper examines teachers' attitudes while creating a TLC in a government high school for several reasons. We hope to describe the difficulty of making meaningful change in a school's culture. McNamara (1995) stated, "Many attempts have been made to change curriculum delivery over the years by introducing new ideas through in-service training. Legislation and management pressure. Many teachers have resisted those pressures to change and changing the teacher attitudes has proven to be very difficult to achieve, some would say impossible to achieve" (p. 17).

Second, it is crucial to examine what teachers think and believe since these beliefs and attitudes shape their practices in classrooms (Richardson, Anders, Tidwell \& Lloyd, 1991). Bruner (1996) and Johnson (1992) went further to explain that not only do beliefs and attitudes shape practices, but these beliefs, once established, influence future practices. Thus, it follows that ignoring teachers' attitudes towards creating a TLC is likely to hinder the successful creation and application of the TLC in government schools where teachers are encouraged to adopt new ideas and reflect on their existing practices.

Third, teachers' opinions and attitudes towards the creation and development of TLC were associated with teaching efficacy. Researchers such as (Cowley \& Meehan, 2001; Dellinger, 2001; Lien \& Chang, 2017;Nolan, 2009) associated teachers' attitudes towards TLC with their teaching efficacy, and suggested to use teachers' attitudes as a 'predictor of their teaching efficacy'.

As teachers' professional learning communities continue to examine current teaching practices, investigate successful teaching methods, monitor progress and improve students' learning, teachers' beliefs in successful teaching practices evolve. These beliefs can be changed when teachers from the same grade level or department collaborate to promote a high quality of learning in each classroom in the school. Teachers' communities can then be formed based on common needs and beliefs which will further help create a larger community of teachers.

It is important that teachers be committed to the success of all students, not only their own students. With this commitment, a TLC can then investigate how to achieve learning outcomes at the various grade levels and collectively determine how teaching practices should be changed to meet specific students' needs throughout the curriculum.

\section{Conceptual Framework}

Several researchers have demonstrated the positive impact of professional learning communities on student's outcomes, teacher's effectiveness and job's satisfaction, and also on the creation of positive learning culture and school climate (Ackerman, 2011; Gates, 2005; Louis, Dretzke\& Wahlstrom, 2010; Kalkan, 2016; Supovitz, Sirinides \& May, 2010; Vescio, Ross \& Adams, 2008). Many attempts to create professional learning communities among teachers are unsuccessful partially due to the absence of research on teachers' attitudes and the reasons behind these unsuccessful attempts. The impact of teachers' attitudes on the creation of a successful teachers' professional learning community is often ignored. Also, like any educational system, the consideration of an effective school's leadership that supports the successful creation of professional learning communities is not studied in depth (Hesmondhalgh, 2002; McGuigan, 2004; Mintzberg, 2009). Therefore, studying the connection between the school's leadership and teachers' attitudes, and the school's attempt to create teachers' learning communities will provide researchers with an insight on how schools succeed in creating a culture of learning communities among their teachers.

Creating a TLC as suggested by Hord and Sommers (2008) requires social interaction and communication among teachers. Key criteria for creating a community of learners among teachers is 
the school's leadership support and the teachers' commitment to work with each other to improve the quality of their instruction and the quality of students' learning. Therefore, to create a TLC in schools, it is critical that teachers engage in an open discussion with their colleagues and share what they know and do in their classrooms. Kuusiaari (2014) conducted data-driven analysis on TLC. The researcher studied teachers' verbal actions during the teams' discussions and suggested that teachers' motivation, self-management and school leaders' guidance should be considered as factors for successful application of TLC.

Therefore, based on the literature, the following figure suggests the levels of creating a successful TLC. To successfully implement a TLC in government schools, we suggest five levels of functioning (figure 1). Level 1 involves teachers' willingness and commitment. Level 2 requires teachers' communication and interaction with each other. Level 3 includes the school leadership's support. Level 4 consists of teachers' autonomy to do what they believe is best for their students. Level 5 comprises the application of the results of the collaboration in classrooms.

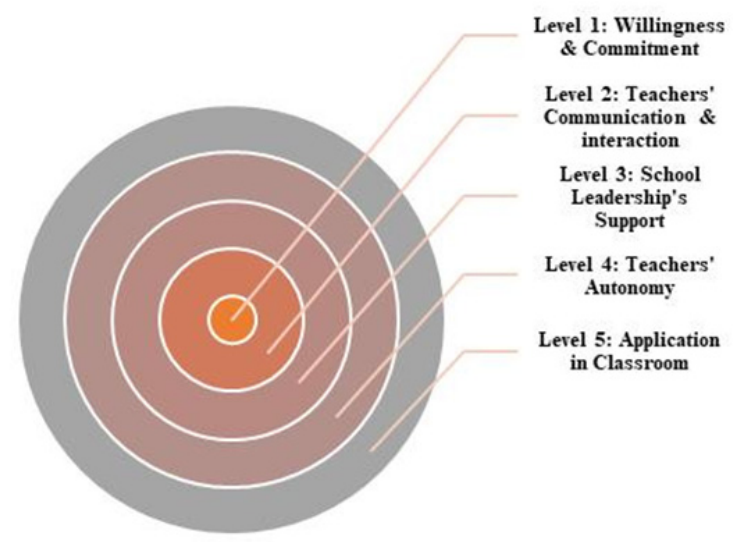

Figure 1: Functional Levels of TLC

\section{Research Methodology}

\subsection{Research Questions}

From the review of the existing literature on teachers' learning communities, a couple of questions were posed which the current study set out to investigate. The current study sought explanations concerning the following research questions:

1. What are English teachers' attitudes toward the application of teachers' learning communities in Kuwait's government schools?

2. What are the challenges facing the application of TLC in government schools in Kuwait?

\subsection{Setting}

A government high school for girls was suggested by the Ministry of Education MOE to be part of the study. The majority of the teachers were Arab nationalities from Egypt, Syria and Jordan. Only one Kuwaiti teacher was teaching in the department. The Curriculum for English Language in high schools (Grades 10 through 12) is a standard-based curriculum of the overall Kuwait National Curriculum, which involves three years of study. In grade 12 students need to pass the National Standardized Examination. The curriculum describes a learning process in which English Language is 
connected to the other subjects of the National Curriculum, focusing on the full development and personal growth of students, guiding students' discussions, stimulating individual thinking, and improving everyday classroom practices.

\subsection{Research Procedures}

Researchers met initially with the principal and the supervisor of the secondary government school in Kuwait to gain access to the teachers in the English Department of this all-girl gender segregated school. Researchers then met with teachers and opened a dialogue with them to allow them to reflect critically on their own teaching practices. Mainly, teachers were asked what practices they liked and what they did not. Later, researchers surveyed the areas of need teachers wanted to work on. Researchers also found that teachers were interested to learn more about the interactive methods for improving literacy levels among students.

Researchers audio and visually recorded teacher focus groups and participant observations, and audio recorded and transcribed individual interviews of teachers, the Head of Department (HOD) and Supervisor (a multi-school coordinator of English subject) at the beginning and at the end of the intervention.

\subsection{Population}

Five teacher pairs were asked to perform demonstrations of research-supported literacy teaching methods to the other teachers in the English Department. A series of professional development workshops were provided by the researchers and consultants. Teachers were paired up (Strauss, \& Corbin, 1990) and given a date and time during which they would present a new research-based teaching method (which they chose and for which they were provided detailed instructions and examples) to their peers. All pairs were then asked to try the new method with a class at a specific date and time and then have their partners observe them and take some notes.

\subsection{Instrumentation}

A semi-structured interview was utilized in which a list of 21 questions were posed to each of the teachers individually, in order to get feedback on their experiences with the TLC experience. The next section provides discussion of the interview results.

\section{Results}

\subsection{Research Question One}

The first question was "What are English teachers' attitudes toward the application of teachers' learning communities in Kuwait's government schools? In general, teachers showed positive attitudes toward TLC as they mentioned some of the benefits of the experience. When teachers were asked at the end what they thought in regard to the demonstrations, six of them said they were beneficial:

The methods were useful for teaching.

The pairs who presented were researching and finding supplementary things.

The application part was the best.

It was very beneficial - the methodological side.

When teachers were asked what they enjoyed most about the opportunity to present to their peers, they had a range of responses from feeling proud that other teachers enjoyed it and 
implemented the strategy to feeling good about getting to know their partners better:

I enjoyed working with my partner, getting to know her better, sharing ideas and thoughts.

It was an excellent experience.

I enjoyed everything, the presentation, working together, gaining more confidence.

Those who presented were asked how they felt about the performance of their partner. Three of them had positive experiences. For example:

She was excellent. She did some research and we shared communication.

However, three teachers indicated a negative response toward the collaborative experience:

It was just a repetition of what we are already doing and despite the interactive nature of both demonstrations I would like to see more interactive, not just listen.

Interestingly, all three presentations included extensive interactive. Participatory practice sessions of the method were demonstrated. One teacher, even though she attended both demonstrations, said they did not occur:

Nothing of the sort happened. There wasn't any title suggesting that there were any new methods used in our meeting. It didn't really happen so I can't express myself about it.

Interestingly, one of the teachers, who had the negative attitude toward the experience was in attendance at both demonstrations, though she sat quietly and did not participate in any of the interactive portions of the demonstrations.

In regard to teachers' willingness, the findings also indicated weak willingness to work in a 'collaborative learning setting', or apply what they learn in their classes. It was obvious that some teachers prefered working individually. Teachers should be motivated to work collaboratively, in order to create an effective learning community in schools:

I do it myself only. I have my own ways.

We like to call ourselves independent, and the feeling is that we should work independently on our lesson plans.

Teachers' motivation to apply what they learn ranged from a desire to improve one's own practice, to helping others become aware of new teaching methods, to complying with administrative expectations. Although all ten teachers signed up for a specific date to do a reading comprehension lesson demonstration, and chose a specific strategy packet provided for them by the researchers, only four teachers (two pairs) and one individual teachers who actually prepared the demonstrations. Those who did share their methods with their peers indicated that their motives were:

To make other teachers aware of different methods.

To benefit my teaching andto learn new terminology.

Team work is easier and more interesting

Because I was asked to.

\subsection{Research Question Two}

The second question was "What are the challenges facing the application of TLC in government schools in Kuwait?" When teachers were asked if they used the instructional methods that were demonstrated, four teachers said they did not use them and six said they did try at least one of them. When researchers visited the school three weeks after the demonstrations to discuss teachers' 
experiences, none of the teachers had tried the new methods.

Teachers' autonomy was another challenge that hinders the application of TLCs. Feeling restricted in what teachers can do in the classroom was a concern for teachers. When asked if they felt free to teach using the best methods of their choosing, responses like the following resulted:

Not all the time. Acting and performing is limited.

As a teacher I have to apply more traditional methods.

My job is to follow the supervision's guidelines and the school's rules.

I think I can, but the problem is to know new techniques or methods with limitations, of course, and we have to ask permission first from management.

I would like to make a class the way the teacher sees it, the way she wants to teach, not what anyone else dictates.

...less interference by others, less restrictions in what you can do or use in the classroom.One size does not fit all.

Another challenge was teachers' lack of working collaboratively. One teacher pointed to some difficulties with her partner:

She was good but I felt at some moments that we weren't on the same page, like we were preoccupied with doing our own part.

This challenge might exist due to lack of teachers' interaction and communication. One teacher pointed out that lack of "time to prepare together" might be one of the reasons.

From the researchers' perspectives, the demonstrations were lively, informative and interactive; teachers were given engaging practice both individually and in small groups after a brief explanation of the theory. Those who participated were making fascinating comments, laughing, asking pertinent questions and contributing excitedly in group discussions. Yet there were three or four teachers who sat quietly, arms folded, looking on and not joining in unless asked specifically to respond to a question. Overall the response to the presentations seemed, from the researchers' perspectives, to have been overwhelmingly positive for those who participated. The researchers asked the presenting teachers how they felt about the way other teachers responded to their demonstrations and their assessments were similar to those of the researchers for the most part:

It was fine, about $80 \%$ enjoyed it.

They were active, happy and involved.

They were taking the role of students and forming groups to discuss the topics.

Results gained from the interviews suggested that teachers in government schools should change the way they see themselves to a more 'lifelong learners':

I received all my education in my country and I feel I'm well prepared to teach English subject in Kuwait.

\section{Conclusion}

Teachers in this research study indicated positive attitudes towards the TLC (McNamara, 1995). However, to improve teachers' willingness to participate in TLCs, teachers must be motivated to participate. Similar results were also shown in previous research such as (Kariyev et. al., 2018; Sakal, Matković\& Tumbas, 2012; Semenikhina \& Drushlyak, 2015). Information collected from this research study provided insights into how teachers' interactions could be facilitated within the context of a Kuwaiti government school's culture. Due to the centralized system in the Ministry of Education MOE, a sense of isolation and a feature of hopelessness were shaping the schools' culture in government schools where teachers lack the autonomy to decide how to teach what they teach. In addition, lack of teachers' collaboration and interaction was also a concern indicated by teachers. 
Teachers explained this lack of collaboration and interaction to lack of time and the workloadStoll and Louis (2007) stated that, to reach a level of teachers' autonomy, the way we provide PD for teachers must be changed. No longer can teachers' PD be viewed as an individual practice operated by the Ministry. It is then explicable as to why teachers in this research study viewed TLC as a challenge. Instead, teachers' PD should be conceptualized as a collaborative learning experience and as a 'self-decided' lifelong development experience.

In order to participate in changing and shaping our teachers' PD through creating a teachers' learning community, we need to study TLCs and examine how effectively they work. This requires leadership's support and teachers' participation in the creation process (Elmore, 2008; Robinson, 2007; Stoll \& Louis, 2007). Hord and Sommers (2008) argued that, for a TLC to happen, school leaders should act less as leaders and more as facilitators and supporters. Teachers should act less as experts in the field and more as learners. Teachers should express their ideas and their voices should be heard in turn. However, such results cannot be achieved within an isolated school's setting. Teachers' PD in government schools are ineffective because of insufficient leadership support.

Training approaches adopted by the government-appointed subject supervisors to raise students' scores, consist of lesson models, seminars and one-shot workshops in and outside the school's setting. There is a sense among government schools' teachers that they have no voice in their PD. As a result, the researchers decided to seek teachers' attitudes at the outset of the creation of the TLC to develop a sense that their voice is heard and their opinions on their teaching practices are taken into consideration. When this sense is established, we open a communication channel for collaboration among teachers to develop their own learning community.

Although research studies concerning teachers' attitudes towards TLCs have increased recently, investigating teachers' use of what they learn in classrooms in relation to their willingness to apply what they learn is needed (King, 2014; Sahlberg, 2011). For instance, there should be more research on the relationship between teachers' practices and what they learn in the LCs. Results reported in this research study showed lack of teachers' application of what they learn from the TLCs. These results were similar to the findings reported in previous literature (Savina, 2015; Semenikhina \& Drushlyak, 2015).

\section{Implications for Professional Development}

Based on the findings, it is thus recommended that in order to successfully create a teachers' community of learning in a government school context in Kuwait, the school should replace the traditional departmental weekly meetings where teachers often listen to one teacher giving a talk on teaching practices to a collaborative learning setting. Unfortunately, the teachers who participated in this research study neither applied the suggested teaching practices that would accommodate students' needs nor observed each other practicing them in their classrooms. Rather, teachers believed that doing what expected from them by the ministry's supervision, would not allow them time to try new practicesIn addition, PD efforts should focus on teachers' willingness and motivation to collaborate before spending time convincing teachers to change the way they teach Hopefully, this research study can provide a platform for discussion on improving teachers' commitment to become life-long learners and to enable teachers to improve their teaching practices which will then lead to improving students' learning outcomes.

Although the findings of this research study relate specifically to a TLC in a government high school in Kuwait, many of these recommendations may be relevant to other educational settings. However, more research is needed on teachers' beliefs and practices as well as means to develop leadership support for TLCs in order to bridge the gap between practice, training and action research.

In conclusion, to successfully implement TLCs in a government Kuwaiti school context, it is recommended that the Ministry of education MOE ensures teachers' willingness to participate in learning communities, encourages teachers' interaction, provides effective leadership support and motivates teachers to apply what they learn in their classrooms with their own students. 


\section{Research Limitations}

There are a number of limitations to this research study worth identifying. It is important to note that the research was conducted in a very specific sociocultural context, where the majority of the teachers are foreigners. This context may have skewed the teachers' perceptions of the school leadership and supervision and its impact on the teachers' willingness to participate in TLCs. This potential bias could explain the noticeable lack of teachers' attention to apply what they learn during the weekly meetings into their classrooms.

The need for teachers to reflect upon their professional development is further underscored by the school leaders and the teachers themselves. However, change can only happen if we agree as a community that teachers' development does actually need transformative preparation. One possible explanation for the lack of teachers' engagement in a school's community is that some of the teacher participated in this research study looked at the researchers as outsiders struggling for acceptance. We did anticipate this limitation and attempted to address it through working on planning the weekly PD sessions with all participants, giving them the autonomy to choose the topics they wanted and the way to present them.

To sum it all up, in the light of the above, it would be recommended to examine the connection between the school's leadership, teachers' willingness to participate in TLCs and teachers' application to what they newly learn during the TLCs.

\section{Acknowledgements}

This research was funded by Kuwait Foundation for the Advancement of Sciences KFAS in the academic year 2017-2018.

\section{References}

Abu Zeid, H., Assadi, N., \& Murad, T. (2017). The effect of junior high school teachers' motivation and willingness to change on the diversity of their teaching methods. Theory and Practice in Language Studies, 12, 1160.

Ackerman, D. (2011). The impact of teacher collaboration in a professional learning community on teacher job satisfaction (Doctoral dissertation). Available from ProQuest Dissertation and Theses database. (UMI No. 3482819).

Beam, M., Chuansheng C., \& Greenberger, E. (2002). The Nature of adolescents' relationships with their 'very important' nonparental adults. American Journal of Community Psychology, 30(2), 305-325.

Benson, P. (2001). Teaching and Researching Autonomy in Language Learning. Harlow, Hong Kong: Longman.

Berlinger-Gustafson, C. (2004). Building Professional Learning Communities. Paper presented at the meeting in support of the Florida Professional Development System Evaluation Protocol.

Bernshtock, G., \& Cohen, G. (2014). The Connection Between Teachers Mastering Teleprocessing Skills and their Willingness to Change: The National Teleprocessing Program, inside: AshetAlkalai, Y., Caspi, A., Eden, S., Gary, Y., Yair, Y. \& Kalman, Y., (eds.), The book of Chase conference for learning technologies studies: The learning Man in the technological era, 64-76, The Open University, Ra'anana.

Boote, D.N. (2006). Teachers' professional discretion and the curricula. Teachers and Teaching: Theory and Practice, 12(4), 461-478.

Bredeson, P., \& Johansson, O. (200o). The school principal's role in teacher professional development. Journal of In-Service Education, 26(2), 385-401.

Bryk, A. (2010). Organizing schools for improvement. The Phi Delta Kappan, 91, 23-30.

Burner, J. (1996). The Culture of Education. Cambridge, MA: Harvard University Press.

Copriady, J. (2014). Self-motivation as a mediator for teachers' readiness in applying ICT in teaching and learning. TOJET: The Turkish Online Journal of Educational Technology, 13(4), 115-123.

Cowley, K. S., \& Meehan, M. L. (2001). Assessing Teacher Efficacy and Professional Learning Community in 19 Elementary and High Schools. A paper presented at the Annual Meeting of the CREATE National Evaluation Institute (1oth, Wilmington, NC, July 19-21, 2001).

Day, C., Harris, A., Hadfield, M., Tolley, H., \& Beresford, J. (200o). Leading Schools in Times of Change. Buckingham: Open University Press. 
Dellinger, A.B., (2001). A study of the Measurement and Sources of Teachers' Self and Collective Efficacy Beliefs in Professional Learning Environments. Dissertation, Louisiana State University.

DuFour, R. (2004). What is a professional learning community? Educational Leadership, 61(8), 6-11.

DuFour, R., \& Eaker, R. (1998). Professional Learning Communities at Work: Best Practices for Enhancing Student Achievement. Bloomington, IN: National Educational Service.

Dutro, E., Chesley, M., Koch, R., Roop, L., \& Wixon, K. (2002). When state policies meet local district contexts: Standards-based professional development as a means to individual agency and collective ownership. Teachers College Record, 104(4), 787-811.

Elmore, R. (2008). Leadership as the Practice of Improvement in Pont, B., D. Nusche and D. Hopkins (eds.), Improving School Leadership, Volume 2: Case Studies on System Leadership, OECD, Paris.

Ford, M. (1992). Motivating Humans: Goals, Emotions, and Personal Agency Beliefs. Newbury Park, CA: Sage.

Fullan, M. (2014). The principal: Three keys to Maximizing Impact. San Francisco, CA: JosseyBass.

Gates, G. (2005). Awakening to school community: Buddhist philosophy for educational reform. Journal of Educational Thought, 39(2), 149-173.

Heck, R. (1992). Principal instructional leadership and the identification of high- and low- achieving schools: The application of discriminant techniques. Administrator's Notebook, 34, 1-4.

Hesmondhalgh, D. (2002). The cultural Industries. London, UK: Sage.

Hord, S. M. (2008). Evolution of the professional learning communities. National Staff Development Council, 29(3), $10-13$.

Hord, S. M., \& Sommers, W. A. (2008). Leading Professional Learning Communities: Voices from Research and Practice. Thousand Oaks, CA: Corwin Press.

Huang, J. (2005). Teacher autonomy in language learning: A review of the research. Research Studies in Education, 3, 203-218.

Ingersoll, R. (2003). Who Controls Teachers' Work? Power and Accountability in American Schools. Cambridge, MA: Harvard University Press.

Johnson, K. E. (1992). The relationship between teachers' beliefs and practices during literacy instruction for nonnative speakers of English. Journal of Reading Behavior, 24(1), 83-108.

Kalkan, F. (2016). Relationship between professional learning community, bureaucratic structure and organizational trust in primary education schools. Educational Science: Theory E Practice, 16, $1619-1637$.

Kariyev, A., Selkebayeva, A., Bespayeva, G., Baigundinova, B., \& Kabdualieva, A. (2018). A study of teacher's readiness for teaching students by methods of interactive learning as a condition for developing students' creative abilities. Revista ESPACIOS, 39(21), 15-31.

King, F. (2014). Evaluating the impact of teacher professional development: An evidence-based framework. Professional Development in Education, 40(1), 89-111.

Kuusiaari, H. (2014). Teachers' collaborative learning: Development of teaching in group discussions. Teacher and Teaching Theory and Practice, 19(1), 50-62.

Lazăr, A. (2013). Learner Autonomy and its implementation for language teacher training. Procedia - Social and Behavioral Sciences, 76(2013), 460-464.

Lien, H., \& Chang, Y. (2017). Professional learning communities: Teachers' beliefs and teaching efficacy. Shi Zi Pei Yu Yu Jiao Shi Zhuan Ye Fa Zhan Gi Kan, 10(1), 75-103.

Leithwood, K. (1992). The move towards transformational leadership. Educational Leadership, 49(5), 8-12.

Littlewood, W. (1997). Autonomy in Communication and Learning in the Asian Context. In KMITT (eds.) Proceedings of the International Conference Autonomy 200o. Thonburi, Thailand: KMITT, 124-140.

Louis, K. S., Dretzke, B., \& Wahlstrom, K. (2010). How does leadership affect student achievement? Results from a national US survey. School Effectiveness and School Improvement, 21(3), 315-336.

McGuigan, J. (2004) Rethinking Cultural Policy. London, UK: Open University Press.

McLaughlin, M. W., \& Talbert, J. E. (2006). Building School-based Teacher Learning Communities. New York, NY: Teachers College Press.

McNamara, S. (1995). Changing Behaviour. London, UK: David Fulton.

Mintzberg, H. (2009). Managing. San Francisco, CA: Berrett-Koehler Publisher.

Nolan, D. E. (2009). A Study of the Relationship of Teachers' Self-efficacy and the Impact of Professional Learning Community as an Organizational Structure. LSU Doctoral Dissertations. 2854. Available Online at: https://digitalcommons.lsu.edu/gradschool_dissertations/2854.

O’Day, J. (2002). Complexity, accountability, and school improvement. Harvard Educational Review, 72(3), 293329.

Pearson, L.C., \& Moomaw, W. (2005). The relationship between autonomy and stress, work satisfaction, empowerment, and professionalism. Educational Research Quarterly, 29(1), 37-53. 
Peters, J. (2004). Teachers engaging in action research: Challenging some assumptions. Educational Action Research, 12(4), 535-556.

Printy, S.M., \& Marks, H.M. (2006). Shared leadership for teacher and student learning. Theory into Practice, 45(2), $125-132$.

Ramos, R. (2006). Considerations on the role of teacher autonomy. Colombian Applied Linguistics Journal, 8, 183202.

Richardson, V., Anders, P., Tidwell, D., \& Lloyd, C. (1991). The relationship between teachers' beliefs and practices in reading comprehension instruction. American Educational Research Journal, 28(3), 559-586.

Robinson, V. (2007). School Leadership and Student Outcomes: Identifying What Works and Why. Australian Council for Educational Leaders. Winmalee, NSW, Australia.

Rogers, E.M. (2003). Diffusion of Innovations (5ed.). New York: Free Press.

Sahlberg, P. (2011). Finnish Lessons: What Can the World Learn from Educational Change in Finland? New York: Teachers College Press.

Sakal, M., Matković, P., \& Tumbas, P. (2012). Willingness to Adopt and Apply Web 2.o Technologies in Secondary Education: Case of Vojvodina. Croatian Journal of Education, 14(4), 743-770.

Sang, G., Valcke, M., Van Braak, J., Tondeur, J., \& Zhu, C. (2011). Predicting ICT integration into classroom teaching in Chinese primary schools: Exploring the complex interplay of teacher-related variables. Journal of Computer Assisted Learning, 27(2), 160-172.

Sarason, S. (1996). Revisiting The Culture of the School and the Problem of Change. New York: Teachers College Press.

Savina, N. (2015). The teachers' willingness to create highly intelligent educational innovations. Social and Behavioral Sciences, 191, 2605-2608.

Schibeci, R., \& Hickey, R. (2003). Dimensions of autonomy: Primary teachers' decisions about involvement in science professional development. Science Education, 88, 119-145.

Semenikhina, O., \& Drushlyak, M. (2015). On the Results of a Study of the Willingness and the Readiness to Use Dynamic Mathematics Software by Future Math Teachers. 11th International Conference on ICT in Education, Research, and Industrial Applications: Integration, Harmonization, and Knowledge Transfer (ICTERI 2015). Lviv, 2015. - P. 21-34.

Smolyaninova, O., \& Bezyzvestnykh, E. (2019). Implementing teachers' training technologies at a federal university: E-portfolio, digital laboratory, PROLog module system. International Journal of Online and Biomedical Engineering, 15(4), 69-87.

Stoll, L., \& Louis, K. (2007). Professional Learning Communities: Divergence, Depth and Dilemmas. Open University Press, Maidenhead.

Strauss, A., \& Corbin, J. (1990). Basics of Qualitative Research: Grounded Theory Procedures and Techniques. Newbury Park, CA: Sage.

Supovitz, J., Sirinides, P., \& May, H. (2010). How principals and peers influence teaching and learning. Educational Administration Quarterly, 46(1), 31-56.

Vescio, V., Ross, D., \& Adams, A. (2008). A review of research on the impact of professional learning communities on teaching practice and student learning. Teaching and Teacher Education, 24(1), 80-91.

Watkins, C. (2005). Classrooms as learning communities: A review of research. London Review of Education, 3(1), $47-64$. 